\title{
Letters
}

Website: www.bmj.com

Email: letters@bmj.com

\section{Low dose aspirin for preventing and treating pre-eclampsia}

\section{Author of editorial did not criticise studies' methodology}

EDITOR-In her editorial discussing the value or otherwise of aspirin for preventing and treating pre-eclampsia Duley wonders why the small trials have such different results from the large trials. ${ }^{1}$ We suggest the following answer.

Evidence based medicine means integrating individual skill with the best available evidence from systematic research. Duley's conclusions, based on several multicentre studies, seem to rely on the conclusions of these studies without her making criticisms of the methodology used.

Firstly, the timing of the start of treatment with low dose aspirin is important. The studies consistently fail to show the percentage of women who were $<16$ weeks pregnant, the crucial time when maximum trophoblastic invasion is taking place (table). This issue was raised by de Swiet in Bower's news article ${ }^{2}$ and by Beaufilis et al. ${ }^{3}$

Secondly, the dose of aspirin used in the later large trials is low. A meta-analysis by Leitich et al (not quoted in the editorial) shows that aspirin was more effective at higher doses (100-150 mg/day) than at lower doses $\left(50-80 \mathrm{mg} /\right.$ day) ${ }^{4}$ It seems that these large studies have looked at the wrong dose of aspirin used at the wrong time of pregnancy.

The editorial's conclusions are based on trials with flawed methodology. The question of whether aspirin given in early pregnancy in an appropriate dose is effective in preventing pre-eclampsia remains unanswered.

J Emeagi Specialist registrar in obstetrics and gynaecology

S Patni Calman trainee in obstetrics and gynaecology H M Tikum Registrar in obstetrics and gynaecology A M Mander Consultant in obstetrics and gynaecology Royal Oldham Hospital, Oldham OLI 2JH Okidok@aol.com

1 Duley L. Aspirin for preventing and treating preeclampsia. BMJ 1999;318:751-2. (20 March.)

Studies of low dose aspirin in pregnancy: dose used and gestational age at time treatment was started

\begin{tabular}{|c|c|c|c|c|}
\hline \multirow[b]{2}{*}{ Study and year } & \multirow[b]{2}{*}{ Dose used (mg) } & \multirow{2}{*}{$\begin{array}{l}\text { Gestational age } \\
\text { when treatment } \\
\text { started (weeks) }\end{array}$} & \multicolumn{2}{|c|}{$\%$ of pregnancies for which treatment was started at: } \\
\hline & & & $<16$ weeks & $<20$ weeks \\
\hline CLASP, $1994^{5}$ & 60 & $12-32$ & Unknown & 62 \\
\hline Italian study, $1993^{6}$ & 50 & $16-32$ & Unknown & 49 \\
\hline BLASP, $1998^{7}$ & 60 & $12-32$ & Unknown & 53 \\
\hline ECPPA, $1996^{8}$ & 60 & $12-32$ & Unknown & 4 \\
\hline JLASP, $1998^{9}$ & 60 & $12-32$ & Unknown & 24 \\
\hline
\end{tabular}
nancy. Lancet 1993:341:396-400.
2 Bower H. Studies reject aspirin for prevention of pre-eclampsia. BMJ 1998:316:885.

3 Beaufils M, Uzan S, Donsimoni R, Colau JC. Prevention of pre-eclampsia by early antiplatelet therapy. Lance $1985 ; 1(8443): 840-2$

4 Leitich H, Egarter C, Hussein P, Schemoer M. A meta-analysis of low dose aspirin for the prevention of intrauterine growth retardation. $\mathrm{Br} J$ Obstet Gynaeco 1997;104:450-9.

5 Collaborative Low-dose Aspirin Study in Pregnancy (CLASP) Collaborative Group. A randomised trial of low dose asprin for prevention and treatment of pre-eclampsia among 9364 pregnant women. Lancet 1994;343:619-29.

6 Anonymous. Low-dose aspirin in prevention and treatment of intrauterine growth retardation and pregnancyinduced hypertension. Italian study of aspirin in preg-

7 Rothell YE Cruickshank JK, Gay MP Griffiths J, Stewart A, Far Pregnancy (BLASP): a randomised trial for the prevention of pre-eclampsia and its complications. Br J Obstet Gynaecol $1998 ; 105(3): 286-92$

8 Estudo Colaborativo para Prevencao de Pre-eclampsia com Aspirina (ECPPA). A randomised trial of low dose aspirin for the prevention of maternal and fetal complications in high risk pregnant women. Br J Obstet Gynaecol 1996;103:39-47

9 Golding J. A randomised trial of low dose aspirin for primiparae in pregnancy. The Jamaica Low Aspirin Study Group (JLASP). Br J Obstet Gynaecol 1998;105(3):293-9.

\section{Author's reply}

EDITOR-I agree that conclusions about the role of low dose aspirin during pregnancy should be based on a systematic review. This review should, however, address a well formulated and clinically relevant question. Here the important question is not whether low dose aspirin prevents pre-eclampsia but whether it has worthwhile benefits for the woman or her child, or both.

As I pointed out, aspirin does reduce the risk of pre-eclampsia, by $10-15 \%$, but this is not reflected in any more substantive benefit, such as a reduction in perinata death or intrauterine growth restriction. Provisional results from a systematic review in preparation for the Cochrane Library support the conclusions in my editorial. This review includes 38 trials involving 30000 women. The review by Leitich et al was based on 13 trials involving $<14000$ women. ${ }^{1}$

If influencing trophoblast invasion was the crucial factor for preventing pretrophoblast invasion associated with preeclampsia are certainly present from about 16 weeks' gestation. It therefore seems that most patients were recruited after the primary pathology developed, which may explain the limited impact of aspirin.

We have started low dose aspirin in the first trimester and have found that antiplatelet treatment started then has much stronger positive effects than the same treat-

eclampsia, aspirin would need to be started early in the first trimester, probably before 12 weeks. Although data have largely been after 20 weeks' gestation, some trend towards a greater effect for women randomised during the first half of pregnancy would be expected if the trophoblast pothesis was correct.

reater benefits, but the evidence to supp this argument is not strong. Fewer than 900 women have been entered into trials ing the higher doses. Results of these risk of pre-eclampsia, but there is insufficient evidence for any reliable conclusions about the effects on perinatal death or intrauterine growth restriction. Also, reassurance about which low aspirin comes from studies in started after 12 weeks. This reassurance cannot automatically be extended to include earlier treatment with higher doses.

Many of the questions about low dose aspirin have now been answered, and it is clear that aspirin does not have the kind of
widespread benefits that were once hoped for. Nevertheless, as Emeagi et al point out, a wissues remain controversial.

Magpie Trial Coordinating Centre, Institute of

Leitich H, Egarter C, Hussein P, Schemoer M. A meta-analysis of low dose aspirin for the prevention of 1997;104:450-9

Trials are needed to determine when treatment should be started

EDITOR-Duley correctly reports that most preventing and treating pre-eclampsia are disappointing in that aspirin has little beneficial effect. ${ }^{1}$ There may be three main of pregnancy. Trophoblast invasion occurs mainly in the first and second trimesters and crat 
ment started in the second trimester. ${ }^{2}$ Indeed, we found that antiplatelet treatment was of limited benefit in the second group of patients, which is consistent with the results of large trials. There were no differences in history between the groups of patients, so this would not account for the difference in data obtained.

A second consideration is that maternal platelets may "escape" from antiplatelet treatment, such that a given treatment becomes less effective. In the same study we used stepped increases of aspirin (up to 75 $\mathrm{mg}$ twice daily), in combination with dipyridamole (from $100 \mathrm{mg}$ three times daily up to $200 \mathrm{mg}$ four times daily) if necessary ${ }^{2}$; this may also have contributed to the good outcomes observed.

Finally, several of the large trials included women at low risk of the disorder, whereas our study concentrated on patients with a high risk of complications of pregnancy. This would also limit the overall efficacy of the treatments used in the trials.

As Duley stated in the editorial, low dose aspirin treatment seems to be safe. The timing and dose of such treatment may make a critical difference in patients at high risk of pre-eclampsia. Appropriate trials are needed to address these questions, as the small studies that generally report positive findings are inadequate for such purposes.

Mark Sullivan Senior lecturer
Michael de Swiet Consultant

Murdoch Elder Consultant

Department of Maternal and Fetal Medicine,

Imperial College School of Medicine, Oueen

Charlotte's and Chelsea Hospital, London W6 0XG

m.sullivan@rpms.ac.uk

Duley L. Aspirin for preventing and treating preeclampsia. BMJ 1999;318:751-2. (20 March.)

2 Sullivan MHF, Clark NAC, de Swiet M, Nelson-Piercy C, Elder MG. Titration of anti-platelet treatment in pregnant women at risk of pre-eclampsia. Thromb Haemos 1998;79:743-6

\section{Training in large bowel cancer surgery}

\section{Trainees' lack of operative experience is} of even greater concern

EDITOR-Aitken et al report three regional audits of training in large bowel cancer surgery in the United Kingdom. ${ }^{1}$ The lack of supervision of surgical trainees that they report constitutes a failure of the training programme, but an equally important failure of the programme seems to be the relative infrequency with which the operations audited (right hemicolectomies and anterior resections) were performed.
According to my calculations from the paper, there were 196 specialist registrar posts at the time of the audit; trainees undertook 1300 right hemicolectomies and 571 anterior resections over four years. If my interpretation of these data is correct, during a single year a trainee could expect to perform fewer than two right hemicolectomies and less than one anterior resection.

I would have thought that this paucity of operative experience would have been of even greater concern to the trainers than the lack of trainees' supervision, yet this was not mentioned at all in the paper.

William H Isbister Consultant

Department of Surgery, King Faisal Specialis Hospital and Research Centre, PO Box 3354 Riyadh 11211, Saudi Arabia isbister@smtpgw.kfshrc.edu.sa

1 Aitken RJ, Thompson MR, Smith JAE, Radcliffe AG, Stamatakis JD, Steele RJC. Training in large bowel cance surgery: observations from three prospective region United Kingdom audits. BMJ 1999;318:702-3. (13 March.)

\section{Author's reply}

EDITOR-I share Isbister's concern at the overall paucity of experience of colorectal cancer surgery shown in these audits. Although a typical trainee's annual experience can be calculated from the trainee numbers, space constraints precluded a full discussion in the article. Any calculation requires some assumptions and must estimate the experience over the six years of specialist training.

Specialist registrars will probably spend at least one year in a post that does not include any coloproctology, and during the first four years they are unlikely to have sufficient experience to perform an anterior resection. Senior house officers are unlikely to undertake any large bowel resections. The table shows the overall experience of a typical specialist registrar. Senior trainees with another specialist interest may spend an additional year in a unit undertaking little or no coloproctology, which will reduce their experience.

The trainees' operative experience in this study fell well below that recently recommended. ${ }^{2}$ The shortfall would be better appreciated if the Surgical Advisory Committee in General Surgery specified a minimum number of training operations. The committee has constantly refused to do this, although specifying a minimum amount of training is normal practice for other professions.

The surgeon is an important independent variable that influences the outcome of surgery for rectal cancer. In these audits the total number of directly supervised anterior resections was under two per trainee. The number of supervised operations must be increased, and this can be done without compromising outcome. Training operations take substantially longer than others, ${ }^{2}$ however, and additional resources must be made available. The royal colleges could emphasise this by insisting that future waiting list initiatives include a training component. This would clearly show to the government the additional costs of training.

Although surgeons recognise the important implications these findings have for emergency general surgery in district general hospitals, neither the public nor the government have fully appreciated how seriously they will affect patient care. One third of all colorectal cancers present as an emergency, and in future many patients will be managed by surgeons whose only exposure to large bowel surgery is the occasional emergency.

Future trainees will have a limited and narrow experience with major surgery. An increase in junior doctors to accommodate a 48 hour week can only worsen the situation.

R James Aitken Senior lecturer

University Department of Surgery, QE II Medical Centre, Nedlands, Perth, WA, Australia

1 Aitken RJ, Thompson MR, Smith JAE, Radcliffe AG, Stamatakis JD, Steele RJC. Training in large bowel cance Stamatakis JD, Steele RJC. Training in large bowel cancer
surgery. Observations from three UK audits. BMJ surgery. Observations fro

2 Crofts TJ, Griffiths JMT, Sharma S, Wygrala J, Aitken RJ Surgical training: an objective assessment of recen changes for a single health board. BMJ 1997;314:891-5.

\section{What is publication?}

\section{Cross references to updates of systematic reviews should be published}

EDITOR-In an editorial Smith mentions the $B M$ fs commitment to publishing versions of systematic reviews already available in the Cochrane Library. ${ }^{1}$ We would like to know whether the $B M J$ also plans to publish substantive updates of such reviews, either electronically or in print.

Reviews and review updates published only in the Cochrane Library are not indexed in Medline or Embase. This would change if abstracts of, or at least cross references to, substantive updates of Cochrane reviews were published in the $B M J \mathrm{~s}$ print edition. Without such indexing much of the medical community may not be aware when updates of meta-analyses become available, since familiarity with the Cochrane Library and access to the Internet are still far from universal.

Average number of resections undertaken annually by a specialist registrar in three areas

\begin{tabular}{|c|c|c|c|c|c|c|c|c|}
\hline & \multicolumn{2}{|c|}{ Elective operation } & \multicolumn{2}{|c|}{ Emergency operation } & \multicolumn{2}{|c|}{ Right hemicolectomy } & \multicolumn{2}{|c|}{ Anterior resection } \\
\hline & Trainee as surgeon & $\begin{array}{l}\text { Consultant as } \\
\text { assistant }\end{array}$ & $\begin{array}{c}\text { Trainee as } \\
\text { surgeon }\end{array}$ & $\begin{array}{c}\text { Consultant as } \\
\text { assistant }\end{array}$ & $\begin{array}{c}\text { Trainee as } \\
\text { surgeon }\end{array}$ & $\begin{array}{c}\text { Consultant as } \\
\text { assistant }\end{array}$ & $\begin{array}{c}\text { Trainee as } \\
\text { surgeon }\end{array}$ & $\begin{array}{c}\text { Consultant as } \\
\text { assistant }\end{array}$ \\
\hline Lothian and Borders & 5.7 & 0.9 & 4.2 & 0.5 & 3.6 & 0.5 & 4.4 & 0.8 \\
\hline Wessex & 9.5 & 0.6 & 3.1 & 0.1 & 4.8 & 0.3 & 4.5 & 0.3 \\
\hline
\end{tabular}


We are making this inquiry with one specific Cochrane review, on malaria chemoprophylaxis, in mind. ${ }^{2}$ Besides being published in the $B M J$, it was commented on in several letters in the journal, ${ }^{3}$ and the Cochrane collaborators have published a substantially revised version of it. $^{4}$ The authors' conclusions regarding the tolerability of mefloquine have changed dramatically, and on some points directly contradict the earlier review published in the $B M J$. The update is based on the same data and the same analysis, but the previously biased conclusions have been corrected. For the first time the authors now also state in their abstract that their meta-analysis provides no evidence for or against higher levels of toxicity and withdrawal with mefloquine compared with other chemoprophylactic regimens.

This example illustrates how important it is that cross references to substantive review updates are as widely accessible as possible. Because online publication will not be indexed it is not an ideal solution. Still, electronic publication of review updates or cross references might be a first step. The more general question of how to index electronic publications in peer reviewed journals will need to be addressed. Will the logical consequence of the $e B M J$ and other electronically expanded peer reviewed journals eventually be a kind of eMedline, an index to peer reviewed electronic publications? Whether such indexing eventually becomes available, and in what form, will certainly influence the fate of this type of publication. It might help to answer the question "What kind of publication is electronic publication in a peer reviewed journal?"

\section{Samuel Erny epidemiologist}

Hilal Maradit-Kremers epidemiologist

Global Drug Safety, F Hoffmann-La Roche, Basle, Switzerland

Samuel.Erny@Roche.Com

Competing interests: Both authors work for Roche, which makes mefloquine.

1 Smith R. What is publication? BMJ 1999;318:142. (16 January.

2 Croft A, Garner P. Mefloquine to prevent malaria: a systematic review of trials. BMJ 1997;315:1412-6.

3 Mefloquine to prevent malaria [letters]. $B M$ J 1998;316:1980-1.

4 Croft AMJ, Garner P. Mefloquine for preventing malaria in non-immune adult travellers. In: Cochrane Library. Issue 1. Oxford: Update Software, 1999

\section{Editor's reply}

Erny and Maradit-Kremers raise a difficult and important issue. We know that manyindeed, perhaps almost all-studies published in medical journals are eventually rendered irrelevant by new studies. Some are flatly contradicted. In the paper world there isn't much that we can do about this. We always look sympathetically on studies that refute material that we've already published, and if we notice a study elsewhere that refutes something we've published then we will try and pick up on it somewhere in the journal-perhaps in Minerva. Inevitably, this is a haphazard process, and we no doubt miss most of the studies that cast doubt on material we've published.
I have argued before that an electronic report on a study remains alive in a way that a paper version never can. ${ }^{1}$ We might thus ask authors when they publish in the $B M J$ to commit themselves to updating their studies, particularly if they are systematic reviews, rather in the way that the Cochrane Collaboration does. This seems, however, an enormous step, and we are not ready to take it yet. What we probably can do at the moment is to ask authors of Cochrane reviews to alert us when they update their review. We could then provide a hotlink from our website to the latest version of the review on the Cochrane database, and if the conclusion of the review is considerably altered then we might ask the authors to send us a note that we could post on our website and perhaps include in the paper version of the journal. We will explore this further.

1 Smith R. Something for everyone. BMJ 1997;315:1696.

\section{Laterality of lower limb amputation in diabetic patients}

\section{Particular attention should be paid to dominant foot at regular review}

EDITOR-Foot ulceration affects as many as $15 \%$ of patients with diabetes; Mancini and Ruotolo estimated that $6-20 \%$ of all patients in hospital with diabetes have foot ulcers. ${ }^{1} \mathrm{~A}$ recent retrospective study of amputations in people with diabetes noted a striking laterality, with nearly all occurring on the right side. ${ }^{2}$ The main predisposing factors to ulceration (peripheral vascular disease, neuropathy, and infection) cannot adequately explain this observation.

We therefore postulated that the excess of right sided amputations in patients with diabetes might be related to right or left sided dominance (that is, right or left footedness) since this might be expected to determine which foot is used most for starting or stopping movement. A dominant foot might be subjected to greater shearing or mechanical stresses or might be more susceptible to injury by accident.

Twenty five patients with unilateral foot ulceration attending a specialist foot clinic at a district general hospital over four weeks were questioned as to whether they were right or left handed/footed, and we recorded the site of their current foot ulceration. Twenty four of the patients were right footed, of whom 18 had ulceration on the right foot. Compared with the expected number of 12 (assuming equal left/right predominance of ulcers), this was significant $\left(\chi^{2}=6, \mathrm{P}<0.02\right)$. The single left footed patient had an ulcer on his left foot.

Our data therefore support Coxon and Gallen's finding that foot ulceration in people with diabetes is more common on the right. Given the relatively small numbers of patients who are truly left footed, a much larger study is required to confirm these observations. We conclude that all diabetic feet at risk should be reviewed regularly, with particular attention being paid to the dominant foot.

P M S Evans Specialist registrar

Department of Medicine, University Hospital of Wales, Cardiff CF4 4XN

C Williams Senior house officer

M D Page Consultant physician

East Glamorgan Hospital, Church Village,

Pontypridd, Mid Glamorgan CF38 1AB

J C Alcolado Senior lecturer

Department of Medicine, University of Wales

College of Medicine, Cardiff CF4 4XN

Alcolado@cardiff.ac.uk

1 Mancini L, Ruotolo V. The diabetic foot: epidemiology. Rays 1997:22:511-23.

2 Coxon JP, Gallen IW. Laterality of lower limb amputation in diabetic patients: retrospective audit. BMJ 1999;318:367. (6 February.)

\section{Study of 15636 patients found no influence of laterality on risk of amputation}

EDITOR-In a retrospective audit of a hospital database Coxon and Gallen found that lower limb amputations among patients attending a diabetic hospital clinic occurred with a startlingly high prevalence on the right side compared with the left (ratio 4:1). They speculated that most people favour their right foot during movement and that this leads to increased physical stresses, and consequently increased amputation, on the right side. We disagree with these findings.

We recently completed a screening programme for a large diabetic population in the north west of England, which included recording information about the site of amputations; it has produced results that conflict with those of Coxon and Gallen. In our study, all primary and secondary healthcare providers in six healthcare districts in the north west were invited to allow a research podiatrist to screen their diabetic patients.

Between 1994 and 1998, diabetic patients aged over 18 were screened when attending their annual review or a specific appointment. In total, 15636 people with diabetes were screened, of whom $190(1.2 \%)$ had a lower limb amputation. Fourteen patients had bilateral amputations, and for 19 the side of the amputation was not specified. Among the remaining 157 patients with unilateral amputations 79 amputations were on the right side and 78 on the left. This shows no difference in laterality of amputation, which was the case at all levels of amputation, whether above knee, below knee, partial foot, or toe amputation.

Our data draw on a large patient base (we included both primary and secondary care) and represent roughly three fifths of the total estimated diabetic population of the participating districts. Our sample differs from that reported by Coxon and Gallen. Their study was based on data collected in a clinical database of hospital diabetic patients, with a prevalence of amputation $(11.7 \%)$ considerably greater than that in our study or other hospital ${ }^{2}$ and population ${ }^{3}$ based studies. It is difficult to reconcile the magnitude of disagreement between the results. 
We agree with the authors that patient education is important to prevent amputations. It would be misguided, however, on the basis of these data, to encourage patients and healthcare professionals to favour the dominant limb in diabetic footcare programmes.

Caroline A Abbott Honorary lecturer caroline@footclinic.demon.co.uk

Ernest R E van Ross Consultant in rehabilitation medicine

Jai Kulkarni Consultant in rehabilitation medicine Disablement Services Centre, Withington Hospital, Manchester M20 8LB

Jonathan E Shaw Research fellow International Diabetes Institute, Caulfield 3162, Victoria, Australia

Anne L Carrington Research scientist Institute for Diabetes Discovery, Branford, CT 06405, USA

Andrew J M Boulton Professor of medicine University Department of Medicine, Manchester Royal Infirmary, Manchester M13 9WL

1 Coxon PJ, Gallen IW. Laterality of lower limb amputation in diabetic patients: retrospective audit. BMJ 1999;318:367. (6 February.)

2 McLeod A, Williams DRR, Sonksen PH, Boulton AJM. Risk factors for foot ulcers in hospital clinic attenders. Diabetologia 1991;34 (suppl 2):A39.

3 Verhoeven S, van Ballegooie E, Casparie AF. Impact of late complications in type 2 diabetes in a Dutch population. Diabetic Med 1991;8:435-8.

\section{Summary of electronic responses}

We received four electronic responses to Coxon and Gallen's article ${ }^{1}$ presenting original data on the laterality of lower limb amputation in patients with diabetes (table) published in the $e B M J .^{2-5}$

The weighted average of right sided amputation is 60\% (95\% confidence interval $57 \%$ to $64 \%$ ). When Coxon and Gallen's study, being an extreme outlier, is excluded no difference between right and left sided lower limb amputation could be found (weighted average 51\% (47\% to 56\%)).

1 Coxon JP, Gallen IP. Laterality of lower limb amputation in diabetic patients: retrospective audit BMJ 1999; 318: 367. (6 February.)

2 Neumann V, Cotter DH, McManus IC. Laterality of lower Neumann V, Cotter DH, McManus IC. Laterality of lower
limb amputation in diabetic patients: retrospective audit. eBMJ 1999;318. http://www.bmj.com/cgi/eletters/318/ 7180/367\#EL7 (accessed 16 April)

3 Abbott CA, Shaw JE, Carrington AL, Boulton AJM. No evidence of an influence of laterality on the risk of amputation in diabetic patients. eBMJ 1999;318. http:// www.bmj.com/cgi/eletters/318/7180/367\#EL5 (accessed 5 March)

4 Connor H. Laterality of lower limb amputation in diabetic Connor H. Laterality of lower limb amputation in diabetic
patients. eBMJ 1999;318. http://www.bmj.com/cgi/ eletters/318/7180/367\#EL6 (accessed 9 April)

5 Bishop AJ. Lower limb amputation. eBMJ 1999;318. http://www.bmj.com/cgi/eletters/318/7180/367\#EL4 (accessed 2 March)

Number of patients with lower limb amputation on left or right side

\begin{tabular}{lcc} 
Author & Right side & Left side \\
\hline Coxon $^{1}$ & 179 & 40 \\
\hline Neumann & \\
\hline Abbott $^{3}$ & 137 & 130 \\
\hline Connor $^{4}$ & 79 & 78 \\
\hline Bishop $^{5}$ & 39 & 34 \\
\hline
\end{tabular}

\section{Inequalities in health}

Policies to reduce income inequalities are unlikely to eradicate inequalities in mortality

EDITOR-In their editorial Davey Smith et al welcome the report of the independent inquiry into inequalities in health but criticise it for not sufficiently tackling the underlying causes of health inequalities, which they see as following from inequalities in wealth, material resources, and especially income. ${ }^{1}$ As partial evidence they refer to the simultaneous increase in income inequalities and social inequalities in mortality in Britain over the past 20 years.

The role of income inequality as the fundamental cause of health inequality may not be as evident as these authors claim. A recent comparative study in the European Union on social inequalities in health among men indicate that the association between income inequality and inequalities in health is weak. For example, in four Scandinavian countries-Finland, Sweden, Norway, and Denmark-social inequalities in morbidity and mortality are roughly comparable to or larger than those in Britain, yet income inequality is much smaller. ${ }^{2}$ Furthermore, in these countries changes in income inequalities were not closely associated with changes in social class differences in mortality. Finland and Denmark have experienced increasing inequalities in mortality since the 1970s. ${ }^{3}$ Both countries, however, had relatively constant income inequalities until at least the early 1990 s. $^{4}$

In Sweden social inequalities in mortality have increased rapidly since the late 1960 s, the increase being especially rapid in the 1970s. In the 1970s and 1980s similar increases were also observed in Norway. ${ }^{3}$ In both countries, however, income inequalities started to increase slowly only after the mid-1980s, ${ }^{4}$ well after the period of most rapid increase in social inequalities in mortality.

These results-together with the well established observation that social inequalities in mortality can also be observed between the social categories at the top of the social hierarchy-cast doubt on the hypothesis that increasing income inequality and poverty are the main underlying cause of social inequalities in mortality. Although policies to reduce income inequalities can be applauded in many countries as a means of increasing social justice and equality, the experience of the Scandinavian countries indicates that such policies are unlikely to be efficient in eradicating inequalities in mortality.

Pekka Martikainen Research fellow

Tapani Valkonen Professor

Population Research Unit, Department of

Sociology, PO Box 18, FIN-00014, University of

Helsinki, Finland

1 Davey Smith G, Morris JN, Shaw M. The independent inquiry into inequalities in health. BMJ 1998;317:1465-6. (28 November.)

2 Mackenbach JP, Kunst AE, Cavelaars EJM, Groenhof F, Geurts IJM, for the EU Working Group on Socioeconomic
Inequalities in Health. Socioeconomic inequalities in morbidity and mortality in western Europe. Lancet $1997 ; 349: 1655-9$

3 Whitehead M, Diderichsen F. International evidence on social inequalities in health. In: Drever F, Whitehead M, ed. Health inequalities. Decennial supplement. London: Stationery Office, 1997. (National statistics series DS No 15.)

4 Hills J. Joseph Rowntree Foundation inquiry into income and wealth. Vol 2. A summary of the evidence. York: Joseph Rowntree Foundation, 1995 .

\section{Early years of development are important} contributors to health inequalities

EDIToR-Davey Smith et al's editorial on the independent inquiry into inequalities in health seemed to miss points that have implications for public policy. ${ }^{1}$ A crucial conclusion in the report relates to the socioeconomic gradients in health: "The penalties of inequalities in health affect the whole social hierarchy and usually increase from the top to the bottom. Thus, although the least well off may properly be given priority, if policies only address those at the bottom of the social hierarchy, inequalities will still exist."

Macintyre makes the point that the social patterning of health and social status is linear. ${ }^{2}$ There is no threshold of deprivation below which people become sick. In countries with national health care, what makes health status a gradient? The report presents evidence that the early years of development are important contributors to health inequalities. Why do some at the bottom of the socioeconomic scale do well? Obviously, the cause is not just income distribution but some more fundamental factor or factors. A recent report from the Canadian national longitudinal survey of children and youth ${ }^{3}$ and the Ontario early years report ${ }^{4}$ have shown, for all social classes, that the quality of parenting has a greater effect than income on early child development.

The report says little about the brain, its development, and early child development and the biological pathway story that may explain some of the health gradient. $^{5}$ Evidence is increasing that the "wiring and sculpting" of the brain in utero and during the first three years set basic competence and coping skills for life. The growing knowledge in the neurosciences, neuroendocrinology, and neuroimmunology is emphasising the importance of the early years. Macintyre, in her proposal to get better understanding of what causes gradients in health, advocates collaboration among biomedical scientists and social scientists to advance our understanding. ${ }^{2}$ Mechanisms and institutions to facilitate and support this cross disciplinary research proposed are needed.

My bet is that two recommendations that relate to the early years, if implemented, will turn out to have the biggest effect on health inequalities in the United Kingdom.

J Fraser Mustard Bell Canada fellow

Founders' Network, Canadian Institute for Advanced Research, Toronto, Ontario M5V 3A8, Canada

1 Davey Smith G, Morris JN, Shaw M. The independent inquiry into inequalities in health. $B M J$ 1998;317:1465-6. (28 November.) 
2 Macintyre S. Understanding the social patterning of health: the role of the social sciences.J Public Health Med 1994:16:53-9.

3 Chao RK, Willms JD. The effects of parenting practices on children's outcomes. In: Willms JD, ed. Vulnerable children in Canada. Edmonton: University of Alberta Press (in press).

4 Mustard JF, McCain MN. Early years study - reversing the real brain drain. Ottawa: Children's Secretariat, Ontario Government, 1999

5 Mustard JF. Society and population health: a state perspective. New York: New Press (in press).

\section{Safer non-cardiac surgery for patients with coronary artery disease}

\section{Preoperative aspirin does increase risk of} perioperative bleeding

EDITOR-In Sonksen et al's editorial on safer non-cardiac surgery for patients with coronary artery disease the authors say that they considered that aspirin does not increase perioperative bleeding. ${ }^{1}$ We were astonished to read this. They based the statement on studies of aspirin's mechanism of action in vitro and the preoperative use of the bleeding time.

The bleeding time correlates poorly with other tests of platelet function and is a poor predictor of bleeding. ${ }^{2}$ The editorial states that aspirin has no effect on platelet aggregation induced by thrombin and high dose collagen. This statement is based only on a study that used flow cytometry. In other studies, laboratory tests of platelet function have shown impaired platelet activity induced by collagen and thrombin after aspirin..$^{3}$ Impaired platelet function in vitro has been documented for more than 72 hours after ingestion of aspirin.

In vitro studies are not predictive of in vivo behaviour, and several clinical studies have clearly shown that aspirin does increase bleeding in both cardiac and non-cardiac surgery. ${ }^{5}$ For prostate surgery the withdrawal of aspirin for at least a week preoperatively has been suggested. ${ }^{5}$ For certain types of surgery, such as neurosurgery, eye surgery, and spinal cord surgery, increased bleeding may have devastating consequences. It is thus inappropriate to suggest that all patients with ischaemic heart disease should receive aspirin in the perioperative period.

Aspirin may well have a role in certain patients with ischaemic heart disease undergoing non-cardiac surgery. Before specific recommendations can be made, however, clinical trials should be done to determine the risks and benefits of this intervention in various settings. In particular, the benefit of preoperative aspirin has to be balanced against the risk of increasing postoperative blood loss, re-exploration for excessive bleeding, and transfusion requirements.

M S Avidan Clinical lecturer in anaesthesia United Medical and Dental Schools, Guy's, King's College and St Thomas's Hospitals' Medical and Dental School, St Thomas's Hospital, London SE1 7EH

B J Hunt Consultant Department of Haematology and Rheumatology, St Thomas's Hospital

Beverley.hunt@gstt.sthames.nhs.uk
1 Sonksen J, Gray R, Hickman PH. Safer non-cardiac surgery for patients with coronary artery disease. $B M$ 1998;317:1400-1. (21 November.)

2 De Caterina R, Lanza M, Manca G, Strata GB, Maffei S, Salvatore L. Bleeding time and bleeding: an analysis of the relationship of the bleeding time test with parameter of surgical bleeding. Blood 1994;84:3363-70.

3 Kallis P, Tooze JA, Talbot S, Cowans D, Bevan DH, Treasure T. Pre-operative aspirin decreases platelet aggregation and increases postoperative blood loss-a prospective, randomised, placebo controlled, double-blind clinical trial in 100 patients with chronic stable angin Eur J Cardiothorac Surg 1994;8:404-9.

4 Kariberg KE Chen J, Egber N, Nowak J Sylvén C ComKarberg KE, Chen J, Lgberg N, Nowak J, Sylven C. Comparison of three independent niste acid. Scand J Clin Lab Invest 1993;53:835-41.

Wiect. Sand Clin Lab hast 19

Wr. PR. Risk of haemorrhage from transurethral prostatec tomy in acetylsalicylic acid and NSAID-treated patients. Scand J Urol Nephrol 1998;322:120-2.

\section{$\beta$ Blockers may be useful, but more evidence is needed}

EDITOR-Sonksen et al's editorial concerning perioperative risk in patients with cardiac disease undergoing non-cardiac surgery reminds readers that this remains an important problem. ${ }^{1}$ We do not agree, however, with some of their comments.

They state that there is compelling direct evidence to support the perioperative use of $\beta$ blockers and refer to the work of Mangano et al. ${ }^{2}$ Mangano et al's randomised controlled trial suggests that $\beta$ blockers may be useful in this population, but its conclusions are not robust. The randomisation of patients was flawed in that those already taking $\beta$ blockers were more likely to be randomised to $\beta$ blockade. The survival analysis achieved significance but excluded patients who died in hospital. If the data are reanalysed on an intention to treat basis, there is a benefit from $\beta$ blockade but it does not achieve significance. The study is highly suggestive of benefit, but more work is needed.

Sonksen et al also suggest that such patients are best cared for in a high dependency unit. There are simply too many of these patients for this to be feasible with current resources, and, as the authors themselves state, the size of the problem is increasing as the population ages. Simple, cheap interventions such as perioperative $\beta$ blockade are a more realistic solution, but such interventions must be properly assessed.

Jasmeet Soar specialist registrar

Simon J Howell senior lecturer

Sir Humphry Davy Department of Anaesthesia,

Bristol Royal Infirmary, Bristol BS2 8HW

Simon.Howell@bristol.ac.uk

1 Sonksen J, Gray R, Hickman PH. Safer non-cardiac sonksery for patients with coronary artery disease. $B M J$ surgery for patie

2 Mangano DT, Layug EL, Wallace A, Tateo I. Effect of atenolol on mortality and cardiovascular morbidity afte noncardiac surgery. N Eng J Med 1996;335:1713-20.

\section{Authors' reply}

Editor-Avidan and Hunt's views about aspirin treatment and perioperative bleeding generally agree with ours (expressed in our editorial)-that large randomised trials are required to document the balance of risk and benefit. We did not claim that aspirin has no effect on perioperative bleeding itself but rather that clinically important excess bleeding attributable to aspirin is unlikely in the high risk population described.

Patients at high risk of cardiovascular complications include those with coronary artery disease who are undergoing high risk surgery. Such surgery includes vascular (especially aortic), intraperitoneal, upper gastrointestinal, and thoracic procedures. ${ }^{1}$ These operations are high risk principally because of the heightened stress response associated with them. Many of the examples of surgical procedures that Avidan and Hunt list would not be classified as high risk. Theirs is therefore quite a different situation from the one we were describing, and hence the risk-benefit analysis would be different.

Avidan and Hunt also challenge our assertion that aspirin treatment has no effect on platelet aggregation induced by high doses of collagen or thrombin; yet the papers they quote do not assess thrombin's effect. Although some debate exists on the ability of collagen to produce irreversible platelet aggregation, at least one authority clearly states: "higher concentrations of collagen and thrombin can stimulate maximal aggregation in the absence of thromboxane A2."'

The situation with thrombin is much clearer: it readily produces irreversible aggregation, even in patients receiving aspirin. ${ }^{3}$ We maintain, therefore, that for a major operation, when numerous agonists (including thrombin) are acting together, aspirin should not cause a clinically important increase in blood loss. Indeed a meta-analysis that included trials involving many different types of surgery (both major and minor) showed only a marginally significant increase in transfusion requirements in patients receiving antiplatelet treatment $(0.7 \%$ v $0.4 \%$; one sided $\mathrm{P}=$ $0.04){ }^{5}$ This is equivalent to three additional patients receiving transfusions per 1000 patients treated. We would argue that the reduction in perioperative cardiac morbidity and mortality produced by perioperative aspirin could be much greater than this, and hence, as we suggested in the editorial, this treatment warrants further investigation.

We agree with Soar and Howell that the case for perioperative $\beta$ blockade is not proved, but the evidence for benefit is strong. Although it may not be possible to care for all these patients in a high dependency unit, we believe that any patient whose clinical history or preoperative investigations suggest readily inducible ischaemia should always be managed in one.

Julian Sonksen Consultant anaesthetist Russells Hall Hospital, Dudley DY1 2HQ

Richard Gray Director

Birmingham Clinical Trials Unit, Medical School, University of Birmingham, Birmingham B15 2TH

Peter Hutton Hickman professor

University of Birmingham Department of Anaesthesia and Intensive Care, Queen Elizabeth Hospital, Birmingham B15 2TH

1 Paul SD, Eagle KA. A stepwise strategy for coronary risk assessment for noncardiac surgery. Med Clin North Am 1995;79:1241-62. 
2 George JN, Shattil SJ. The clinical importance of acquired abnormalities of platelet function. $N$ Engl $J$ Med 1991;324:27-39.

3 Packham MA. Role of platelets in thrombosis and hemostasis. Can J Physiol Pharmacol 1994;72:278-84.

4 Roth GJ, Calverley DC. Aspirin, platelets, and thrombosis: theory and practice. Blood 1994;83:885-98.

Antiplatelet Trialists' Collaboration. Collaborative overview of randomised trials of antiplatelet therapy-III: Reduction in venous thrombosis and pulmonary embolism by antiplatelet prophylaxis among pulcical and medical patients. $B M J$ 1994;308:235-46.

\section{Health care is not a human right}

EDITOR-The Tavistock Group has invited comments on its document on shared ethical principles. ${ }^{1}$ I would challenge its first major principle-that health care is a human right.

A human right is a moral right of paramount importance applicable to every human being. There are several reasons why health care should not be considered a human right.

Firstly, health care is difficult to define. It clearly encompasses preventive care (for example, immunisation), public health measures, health promotion, and medical and surgical treatment of established illness. Is the so called human right to health care a right to basic provision of clean water and adequate food, or does everyone in the world have a right to organ transplantation, cosmetic surgery, infertility treatment, and the most expensive medicine? For something to count as a human right the minimum requirement should surely be that the right in question is capable of definition.

Secondly, all rights possessed by an individual imply a duty on the part of others. Thus the right to a fair trial imposes a duty on the prosecuting authority to be fair. On whom does the duty to provide health care to all the world's citizens fall? Is it a duty on individual doctors, or hospital authorities, or governments, or only rich governments? It is difficult to see how any provision of benefits can be termed a human right (as opposed to a legal entitlement) when to meet such a requirement would impose an intolerable burden on others.

Thirdly, the philosophical basis of all human rights has always been shaky. Liberalism and humanism, the dominant philosophies of Western democracies, require human rights. Religion requires a God, but this is not in itself evidence of God's existence. Most people can see some advantage in maintaining the concept of civil and political rights, but it is difficult to find any rational or utilitarian basis for viewing health care in the same way.

To propose that health care be considered a human right is not only wrong headed, it is unhelpful. Mature debate on the rationing and sharing of limited resources can hardly take place when citizens start from the premise that health care is their right, like a fair trial or the right to vote. I suspect that the proponents of the notion think that to claim health care as a human right adds some kind of weight or authority to the idea that health care, and by extension healthcare professionals, is important. A more humble approach would achieve more in the long run.

Philip Barlow Consultant neurosurgeon Southern General Hospital, Glasgow G51 4TF

1 Smith R, Hiatt H, Berwick D. Shared ethical principles for everybody in health care: a working draft from the Tavistock Group. BMJ 1999;318:248-51. (23 January.)

\section{Opiate detoxification under anaesthesia}

No confusion and distress were intended

Editor-Our letter ${ }^{1}$ was a response to Brewer's own letter ${ }^{2}$ and reported reasons why we had decided not to collaborate with him on the study of opiate detoxification under anaesthesia. Brewer has expressed concern to us that our expression of "dislike of Brewer's proposal that NHS funds should be diverted from the NHS into his private treatment business" raised an inference of professional impropriety on his part and implied that his motives for wanting to collaborate were at least in part to enrich himself with NHS funds, and that our earlier mention of the need for "objectivity and equipoise" in medical researchers could be considered to be an implication that he might in some way behave dishonestly if a trial were to be conducted. We accept that Brewer's offers of collaboration were made on an ordinary friendly academic basis. We regret that we misunderstood this, and we apologise if our letter seemed to cast doubt on his probity and objectivity. It was certainly not our intention to do so, and we regret any distress that our letter may have caused.

Our letter also reported our concerns about the potential hazards of the procedure. The final sentence of our letter had been altered by the $B M J$ without consultation with ourselves. The original letter had referred to "several deaths, whether directly or indirectly related, including one in not dissimilar circumstances under Brewer's own care ...." The omission of the qualifying phrase "in not dissimilar circumstances" left open the implication that the death had occurred during detoxification under anaesthesia, which is not correct. The death has already been described by Brewer ${ }^{3}$ as was referenced in our letter': the detoxification, had also involved sudden antagonist challenge, although it had been undertaken under heavy sedation, not anaesthesia, and in a psychiatric rather than an intensive care treatment setting. We regret any confusion caused to readers and distress experienced by Brewer.

John Strang Director

Jenny Bearn Consultant psychiatrist

Michael Gossop Head of research (addiction directorate)

National Addiction Centre, The Maudsley/Institute of Psychiatry, London SE5 8AF

\footnotetext{
Strang J, Bearn J, Gossop M. Potential collaborators saw various problems with study of detoxification under anaesthesia. BMJ 1999;318:264. (23 January.)
}

2 Brewer C. Opiate detoxification under anaesthesia. BMJ 1998:316:1983-4.

3 Brewer C. Naltrexone in the prevention of relapse and opiate detoxification. In: Brewer C, ed. Treatment options in addiction: medical management of alcohol and opiate abuse. London: Gaskell, 1992:54-62.

\section{Apologies accepted}

EDITOR-I am pleased that Strang et al have apologised but displeased that they have taken so long to do so. Jonathan Williams of the Brighton NHS Trust had some discussions with Strang and Bearn late in 1996 and can confirm that our preferred option was a controlled trial in an NHS unit. My recent review of the literature on rapid opiate detoxification $^{1}$ was described as "careful" (which implies equipoise and objectivity) in an editorial ${ }^{2}$ by one of the authorities cited by Strang et al.

While I hope that their hurtful and unwarranted remarks will soon be forgotten, some additional points still need to be made. Strang et al were purportedly replying to my letter commenting on their earlier editorial. However, in concentrating exclusively on their reasons for not responding to my offer to collaborate in research into rapid opiate detoxification under anaesthesia they dealt with a minor, non-clinical issue which took up less than $5 \%$ of that letter. They ignored the three important clinical points which occupied the remaining $95 \%$. These were the following. Firstly, this is a technique not just for facilitating, humanising, and shortening opiate detoxification (especially for patients who cannot complete or even contemplate conventional detoxification programmes) but also for facilitating transfer to supervised naltrexone treatment, which significantly reduces the risk of relapse. ${ }^{45}$ Secondly, pain relief is a traditional and praiseworthy medical activity which should not be denied to heroin addicts just because they are widely disliked by doctors. Thirdly, we accept the small risks of anaesthesia and other invasive techniques in equally "non-essential" contexts such as dental phobia (not to mention cosmetic surgery and childbirth). Strang sent me the editorial in draft for my suggestions. I suggested, unfortunately in vain, that he should include these points.

With the fairly conventional current inpatient detoxification programme at the National Addiction Centre, some 20\% of patients leave prematurely. ${ }^{6}$ By combining rapid opiate detoxification under anaesthesia and similar techniques with naltrexone implants, not only is the completion rate $100 \%$ but relapse in less than five weeks is virtually impossible. ${ }^{7}$ Controlled studies in public hospitals, in which I tried to interest Strang over four years ago, are being done in Spain, Australia and the Netherlands and the preliminary results are encouraging. ${ }^{8}$ I and my anaesthetist colleagues remain willing to share our experience with Strang et al.

Colin Brewer Medical director

Stapleford Centre, London SW1W 9NP

1 Brewer C. Ultra-rapid, antagonist-precipitated opiate withdrawal under general anaesthesia or sedation. Addiction Biol 1997;2:291-302.

2 Kleber H. Ultra rapid opiate detoxification. Addiction 1998;93:1629-33. 
3 Brewer C. Opiate detoxification under anaesthesia. BMJ 1998;316:1933-4.

4 Gerra G, Marcato A, Cacavari Rs. Clonidine and opiate receptor antagonists in nthe treatment of heroin addiction.J Subs Abuse Treat 1995;12:35-41.

5 Cornish JW, Metzger D, Woody GE. Naltrexone pharmacotherapy of opioid dependent federal probationers. J Subs Abuse Treat 1997;14:529-34.

6 Bearn J, Gossop M, Strang J. Accelerated lofexidine treatment regimen compared with conventional lofexidine and methadone treatment for in-patient opiate detoxification. Drug and Alcohol Depend 1998;50:227-32.

7 Foster J. Brewer C. Naltrexone implants completely Foster J, Brewer C. Naltrexone implants completely prevent early (one month) relapse after opiate detoxifica-
tion. Addiction Biol 1998;4:232. (Abstract.)

8 Currie J. Randomised trial of sedation-assisted vs. anaesthesia-assisted naltrexone induction: outcome after six months. Paper presented at conference on: Rapid opiate detoxification under anaesthesia or sedation and postdetox management using naltrexone. Clinical, neurobiological, pharmacological and psychosocial aspects. Berlin, June 17-18, 1999.

\section{Policy of "hands poised" care by attendant in normal birth is not recommended}

EDITOR-In their article on care in normal labour Steer and Flint described a trial of management of delivery of the baby's head (the HOOP ("hands on or poised") study). ${ }^{1}$ The results of that study were published last year. ${ }^{2}$

The trial compared a policy of hands on care with one of hands poised care. In hands on care the attendant at a normal birth had one hand on the baby's head to apply pressure to control the delivery and the other on the woman's perineum, with the use of lateral flexion once the head was delivered to facilitate birth of the shoulders; in hands poised care the attendant guided the woman through the birth without touching the baby's head or the woman's perineum and kept hands poised, ready to apply pressure if necessary.

\section{Advice to authors}

We prefer to receive all responses electronically, sent either directly to our website or to the editorial office as email or on a disk. Processing your letter will be delayed unless it arrives in an electronic form.

We are now posting all direct submissions to our website within 72 hours of receipt and our intention is to post all other electronic submissions there as well. All responses will be eligible for publication in the paper journal.

Responses should be under 400 words and relate to articles published in the preceding month. They should include $\leqslant 5$ references, in the Vancouver style, including one to the BMJ article to which they relate. We welcome illustrations.

Please supply each author's current appointment and full address, and a phone or fax number or email address for the corresponding author. We ask authors to declare any competing interest. Please send a stamped addressed envelope if you would like to know whether your letter has been accepted or rejected.

Letters will be edited and may be shortened.

www.bmj.com

letters@bmj.com
Altogether 5471 women were randomised to the study. Women allocated to the hands on group were less likely to report pain at 10 days after the birth than women allocated to the hands poised group (910 $(34.1 \%)$ v 823 (31.1\%); relative risk 1.10 (95\% confidence interval 1.01 to 1.18$)$ ). The rate of episiotomy was higher in the hands on group (351 (12.9\%) v $280(10.2 \%) ; 0.79$ (0.65 to 0.96)) and the rate of manual removal of the placenta was lower $(42(1.5 \%)$ v $71(2.6 \%) ; 1.69$ (1.02 to 2.78$)$ ). No other significant differences were found between the allocated groups.

In the light of the evidence from this study, a policy of hands poised care is not recommended. If women are actively choosing this form of care, however, midwives should be given clinical education to enable effective, safe practice. Where hands poised care is used, audit of third stage outcomes should be maintained; where hands on care is offered, audit of episiotomy is desirable.

Jo Garcia Social scientist

National Perinatal Epidemiology Unit, Radcliffe Infirmary, Oxford OX2 6HE

Jo.Garcia@perinatal-epidemiology.oxford.ac.uk

Competing interests: None declared.

On behalf of the HOOP Study Group.

1 Steer P, Flint C. ABC of labour care: physiology and management of normal labour. BMJ 1999;318:793-6. (20

2 McCandlish R, Bowler U, van Asten H, Berridge G, Winter $\mathrm{C}$, Sames L, et al. A randomised controlled trial of care of the perineum during the second stage of normal labour. Br J Obstet Gynaecol 1998;105:1262-72.

\section{Delays experienced by doctors suspended by GMC}

\section{Delays are worst for doctors on short} term contracts

EDITOR-I am sending this letter on behalf of a trainers group. We are concerned at the delay experienced by doctors who are called before the General Medical Council's disciplinary hearing system. We have particular concern for doctors who at the time of suspension are employed on short term contracts, particularly general practice registrars.

We understand that at the moment the system takes about 18 months from the time of complaint or suspension. Whereas career grade medical practitioners are suspended on full pay, doctors on short term contracts receive no income after the end of their contract. As they are unable to practise they suffer severe financial losses pending the result of the inquiry.

A delay of 18 months for processing complaints seems unacceptable. We understand that some initial delay is necessary to allow full investigation of the complaint, but for accuracy this should occur as speedily as possible. The case should then be able to proceed to resolution at the earliest opportunity. We fail to see how a delay of more than six months to complete the case can be justified.
It is not clear what the bottlenecks in the system are, but we appeal to the profession to ensure that they are overcome so that the public and the profession can receive a fair outcome more efficiently than at present.

Steve Cox Vocational training scheme course organiser Chiltern Postgraduate Medical Centre, Wycombe Hospital, High Wycombe, Buckinghamshire HP11 2TT

\section{GMC's reply}

EDITOR-I take it that Cox's concerns are particularly about the time taken by those cases (a small minority of complaints received) that are referred by the preliminary proceedings committee of the General Medical Council to the professional conduct committee. The points that Cox has raised need to be seen in the context of a steep increase in the number of complaints against doctors-3000 in 1998 compared with around 1000 five years earlier. The council is recruiting more staff to deal with complaints at the same rate.

Once a decision has been taken to refer a case to the preliminary proceedings committee there will inevitably be some delay in listing the case while barristers are instructed, the charge drafted, and documents served on the doctor. The interests of fairness also demand that the doctor and his or her lawyers should be given sufficient time to prepare their defence. I recognise, however, that delays can also occur because of the large numbers of cases awaiting hearings. At the end of March 1999, 100 cases that had been referred for inquiry had not yet been considered by the professional conduct committee. The time that had elapsed since they had been referred to the committee was: 0-3 months, 34 cases; 3-6 months, 15; 6-12 months, 37 ; and over 12 months, 14 .

Time also elapses between the original complaint to the General Medical Council and referral to the professional conduct committee. Again, there are legitimate reasons for that-the need to obtain documents and statements and make inquiries to see if there is a case to answer-but we are not complacent and are looking critically at our processes to see if they can be speeded up without any threat to natural justice.

We have taken steps to reduce the time that doctors wait for their cases to be heard by the professional conduct committee. The committee now sits more frequently; additional sessions have been held; and more sessions are planned this year and in 2000 , when we plan to run two panels simultaneously on most days.

These efforts will, we believe, reduce the waiting time and will, as Cox says, be fairer to both the public and the profession.

D Irvine President General Medical Council, London W1N 6JE

\section{Rapid responses $\quad e B M J$ Correspondence submitted electronically is available on our website www.bmj.com}

